OPEN ACCESS

Edited by:

Jian Zhang,

Wenzhou University, China

Reviewed by:

Zhang Wenchang,

Institute of Microelectronics (CAS),

China

Kui Wang,

Sichuan University, China

${ }^{*}$ Correspondence:

Feng Xu

fccxuf@zzu.edu.cn

Xiaonan Yang

iexnyang@zzu.edu.cn

Specialty section: This article was submitted to Biosensors and Biomolecular

Electronics,

a section of the journal

Frontiers in Bioengineering and

Biotechnology

Received: 10 January 2022

Accepted: 24 January 2022

Published: 23 February 2022

Citation:

Chen B, Li Y, Xu F and Yang X (2022)

Powerful CRISPR-Based Biosensing

Techniques and Their Integration With

Microfluidic Platforms.

Front. Bioeng. Biotechnol. 10:851712.

doi: $10.3389 /$ fbioe.2022.851712

\section{Powerful CRISPR-Based Biosensing Techniques and Their Integration With Microfluidic Platforms}

\author{
Bing Chen ${ }^{1}$, Ya $\mathrm{Li}^{1}$, Feng $\mathrm{Xu}^{1 *}$ and Xiaonan $\mathrm{Yang}^{2 *}$ \\ ${ }^{1}$ Department of Gastroenterology, The First Affiliated Hospital of Zhengzhou University, Zhengzhou, China, ${ }^{2}$ Institute of Intelligent \\ Sensing, Zhengzhou University, Zhengzhou, China
}

In the fight against the worldwide pandemic coronavirus disease 2019 (COVID-19), simple, rapid, and sensitive tools for nucleic acid detection are in urgent need. PCR has been a classic method for nucleic acid detection with high sensitivity and specificity. However, this method still has essential limitations due to the dependence on thermal cycling, which requires costly equipment, professional technicians, and long turnover times. Currently, clustered regularly interspaced short palindromic repeats (CRISPR)-based biosensors have been developed as powerful tools for nucleic acid detection. Moreover, the CRISPR method can be performed at physiological temperature, meaning that it is easy to assemble into point-of-care devices. Microfluidic chips hold promises to integrate sample processing and analysis on a chip, reducing the consumption of sample and reagent and increasing the detection throughput. This review provides an overview of recent advances in the development of CRISPR-based biosensing techniques and their perfect combination with microfluidic platforms. New opportunities and challenges for the improvement of specificity and efficiency signal amplification are outlined. Furthermore, their various applications in healthcare, animal husbandry, agriculture, and forestry are discussed.

Keywords: CRISPR/Cas systems, biosensor, microfluidic techniques, isothermal amplification, nucleic acid detection

\section{INTRODUCTION}

Coronavirus disease 2019 (COVID-19), which was caused by severe acute respiratory syndrome coronavirus 2 (SARS-CoV-2), has resulted in more than five million global deaths to now (WHO Coronavirus Disease (COVID-19) Dashboard https://covid19.who.int (2021). In the fight against this worldwide pandemic disease, the great demands of simple, rapid, and sensitive tools for virus diagnosis promoted the rise of nucleic acid detection platforms. Quantitative PCR with reverse transcription (RT-qPCR), as a classic method for nucleic acid detection with high sensitivity and specificity, is still the gold standard (Ravi et al., 2020; Vandenberg et al., 2021). However, this method still has essential limitations due to the dependence on the accomplishment of amplification and reverse transcript processes including $\sim 30$ cycles of denaturation, annealing, and extension steps, which could be accompanied by amplification bias and cross-contamination. Moreover, costly equipment, professional technicians, and essential turnover times are required for the thermal cycles.

Currently, clustered regularly interspaced short palindromic repeats (CRISPR) based biosensors have been developed as powerful tools for nucleic acid sensing and widely applied to the rapid diagnosis of infectious pathogens (Kellner et al., 2019; Qin et al., 2019; Broughton et al., 2020; Ding R. 
et al., 2021; Song F. et al., 2021; Chen et al., 2021c; EscalonaNoguero et al., 2021; Ge et al., 2021) and the detection of DNA or miRNAs associated with diseases such as cancer (Li B. et al., 2021; Wang et al., 2021c; Chen Y. et al., 2021). These biosensors rely on the CRISPR systems containing CRISPR-associated proteins (Cas) with nonspecific endonuclease activity to efficiently cleave specific targets via guide RNAs (gRNAs) (Cong et al., 2013; Mali et al., 2013; van der Oost, 2013). CRISPR systems are highly sensitive and specific; for example, Cas13 orthologs showed a 50-fM detection sensitivity of target RNA input (about 600,000 molecules) (Gootenberg et al., 2017). However, common CRISPR systems cannot reach clinical diagnostic demand as singlemolecule sensing. The CRISPR-based biosensors are usually integrated with pre-amplification steps to boost the detection. Considering the device limitation of PCR methods, portable and isothermal amplification methods are preferred adoptions for preamplification and showed great potential with the capabilities to perform under easily controlled conditions, even at physiological temperature (Vincent et al., 2004; Piepenburg et al., 2006; Tomita et al., 2008). Moreover, with the advances of aptamers used in the CRISPR systems, ultrasensitive protein detection and protein/small molecular interaction identification can also be facilitated (Wang et al., 2020; Zhang K. et al., 2021; Wang et al., 2021d; White et al., 2021) (e.g., alkaline phosphatase, polynucleotide kinase/ phosphatase, and chemokine).

Microfluidic platform, also known as the micro total analysis system ( $\mu \mathrm{TAS}$ ), has the ability to integrate sample processing and analysis on a single chip, reducing the consumption of sample and reagent and increasing the detection throughput (Manz et al., 1990; Dong et al., 2019). These features make it feasible to assemble CRISPR-based biosensors into streamlines with operational procedures and without the requirement of professional personnel, especially developed for point-of-care (POC) devices (Yin et al., 2019; Li Z. et al., 2021). This review provides an overview of recent advances in the development of CRISPR-based biosensing techniques and their perfect combination with microfluidic platforms. Furthermore, their various applications including medical diagnostics, disease screening, food-safety monitoring, and crop genotyping are outlined.

\section{CRISPR-BASED BIOSENSING TECHNIQUES}

CRISPR-Cas system was found to be associated with immune response in bacteria or archaea, and the genomic element, CRISPR sequence, was first discovered in Escherichia coli (Ishino et al., 1987). CRISPR-Cas system functioned in the adaptive immunity of microorganisms via targeting and degradation of foreign nucleic acid, so as to destroy virus invaders (Lander, 2016). There are three main stages in the CRISPR-Cas immune response: adaptation, when Cas protein recognizes and binds to the target DNA; expression, when the CRISPR array is transcribed into CRISPR RNAs (crRNAs); and interference, when crRNA guided Cas nuclease to cleave and inactivate the invading virus or plasmid genome (Makarova et al., 2020) evolutionary. In 2013, Cong et al. and Mali et al. identified that the bacterial CRISPR system can be applied in mammalian genomes engineering (Cong et al., 2013; Mali et al., 2013). They reported a type II Cas nuclease, Cas9, which can break specific double-strand DNA (dsDNA) targets via RNA-guided process and be used for directed mammalian genome editing. After that, the CRISPR system was booming in the next decade with the rapid development and improvement of efficiency, specificity, and fidelity and provided powerful tools for sophisticated genetic engineering in fundamental research and practical applications, especially in medical and agricultural fields. Moreover, components in the CRISPR system cost very low; for example, the gRNA sequence is cheap to synthesize, the quencher has a fixed sequence without the need to be redesigned and ordered for each new target, and the Cas proteins can be produced in bulk (Kellner et al., 2019). With these natural advantages, CRISPR systems were widely harnessed for biosensing approaches, blossomed in the nucleic acid detection for disease diagnoses, such as Specific High-Sensitivity Enzymatic Reporter Unlocking (SHERLOCK) (Gootenberg et al., 2017; Gootenberg et al., 2018; Kellner et al., 2019), one-HOur Low-cost Multipurpose highly Efficient System (HOLMES) (Li et al., 2018; Li L. et al., 2019), and DNA endonuclease-targeted CRISPR trans reporter (DETECTR) (Chen et al., 2018; Broughton et al., 2020).

\section{Available CRISPR Systems for Biosensing}

Since the Cas proteins showed remarkable diversity, CRISPR systems were divided into two classes according to the effector modules composed of multiple Cas proteins (class 1, involving types I, III, and IV) or single multidomain protein (class 2, involving types II, V, and VI) (Makarova et al., 2020). Although class 1 systems extensively exist in microorganisms, their applications were limited by the need for multi-subunit effectors (Liu et al., 2021a). Thanks to the efforts on the discovery of novel systems, highly efficient and simplified CRISPR-based biosensing methods were designed. Commonly used natural Cas nucleases and their variants were described as follows.

\section{Cas9}

Cas9, belonging to type II systems, can induce specific doublestrand breaks (DSBs) in target DNA through a dual-RNA-guided process, in which a fusion of crRNA and its base-paired transactivating crRNA (tracrRNA) directs Cas9 to the complementary sequence (Gasiunas et al., 2012; Jinek et al., 2012). In biosensing assay, the dual-tracrRNA:crRNA can be designed as a functional artificial chimera with demand. Except for the tracrRNA:crRNA gRNAs, a proto-spacer-adjacent motif (PAM) sequence NGG (N $=\mathrm{A}, \mathrm{T}, \mathrm{C}$, or $\mathrm{G}$ ) was needed. When Cas9-gRNA complex recognizes PAM, the spacer of gRNA pairs with the target DNA strand to form an "R-loop" structure, after which the cleavage of DNA strands is accomplished with a blunt-end DSB 3 bp upstream of the PAM into the protospacer (Jinek et al., 2012; Cong et al., 2013; Mali et al., 2013). Cas9 has HNH and RuvC nuclease domains, which cleave the complementary strand and noncomplementary strand, respectively. When either $\mathrm{HNH}$ or RuvC domain was inactivated, called Cas9 nickase (nCas), only one DNA strand can be cleaved without DSBs (Anzalone et al., 2019). When both domains were inactivated, 
dead Cas9 (dCas9) was created, which is still able to bind to specific DNA targets but defective in nuclease activity (Qi et al., 2013). Although dCas9 cannot cleave target DNA like wild-type Cas9, it provides a scaffold for recruiting effectors to specific sites.

A major barrier to the applications of CRISPR is the "offtarget" effects, referring to the cleavage at unintended sites because of the nuclease tolerating mismatches between gRNA and off-target DNA (Liu et al., 2021a). To deal with this issue, marked improvements were made in gRNA modification, protein and guide engineering, and novel enzymes screening (Tycko et al., 2016). For example, truncated gRNAs (Tru-gRNAs) with shorter regions of target complementarity $<20$ nucleotides in length ( $\mathrm{Fu}$ et al., 2014), hp-sgRNAs designed with a hairpin onto the spacer region (Kocak et al., 2019), and CRISPR hybrid RNA-DNA (chRDNA) guides (Donohoue et al., 2021) have been reported to effectively optimize Cas9 specificity and preserve on-target activity. Nuclease engineering, such as using paired nCas9 nickases or fusing dCas9 with the FokI nuclease domain, can also improve specificity (Guilinger et al., 2014; Shen et al., 2014; Tsai et al., 2014). Another strategy is to screen novel high-fidelity Cas9 variants that are developed by rational design or directed evolution (Kim et al., 2020; Schmid-Burgk et al., 2020), providing useful instructions to their application in different situations.

Despite the robust activity, the specific requirement of PAM in DNA targeting limits the flexibility and applications of Cas9 (Anzalone et al., 2019). Ongoing efforts were made to realize PAM-free nucleases through natural ortholog mining and protein engineering (Collias and Beisel, 2021).

\section{Cas12}

Cas12, a kind of type V nuclease, contains a RuvC-like domain only and cleaves both target and non-target strands, introducing a staggered DNA DSB (Zetsche et al., 2015). Cas12a (first reported as Cpf1) processes pre-crRNA into mature crRNA and cleave target DNA independent of additional RNA species, greatly simplifying the editing design (Zetsche et al., 2015; Zetsche et al., 2017). Cas12a has short T-rich PAM recognition sites, rather than the G-rich PAM following the target DNA for Cas9, expanding the targeting range (Zetsche et al., 2015). Cas12b (formerly known as C2c1) contains RuvC-like endonuclease domains distantly related to Cas12a but depends on both crRNA and tracrRNA for DNA cleavage (Strecker et al., 2019; Ming et al., 2020). Although Cas12a offers unprecedented flexibility, more compact versions are explored and engineered to extend the application. For example, Cas12c, Cas12h, and Cas12i have been identified with RNA-guided dsDNA interference activity (Yan et al., 2019). Cas12g was characterized by RNA-guided collateral ribonuclease and singlestrand deoxyribonuclease activities (Yan et al., 2019). Cas12f (also known as Cas14) nucleases cleave single- and dsDNA targets triggered by a $5^{\prime} \mathrm{T}$ - or C-rich PAM sequence (Harrington et al., 2018; Karvelis et al., 2020; Bigelyte et al., 2021; Xu X. et al., 2021; Takeda et al., 2021).

\section{Cas13}

Cas13 belongs to type VI CRISPR-Cas systems and contains two Higher Eukaryotes and Prokaryotes Nucleotide-binding (HEPN) domains (Shmakov et al., 2015). Cas13a, which was initially
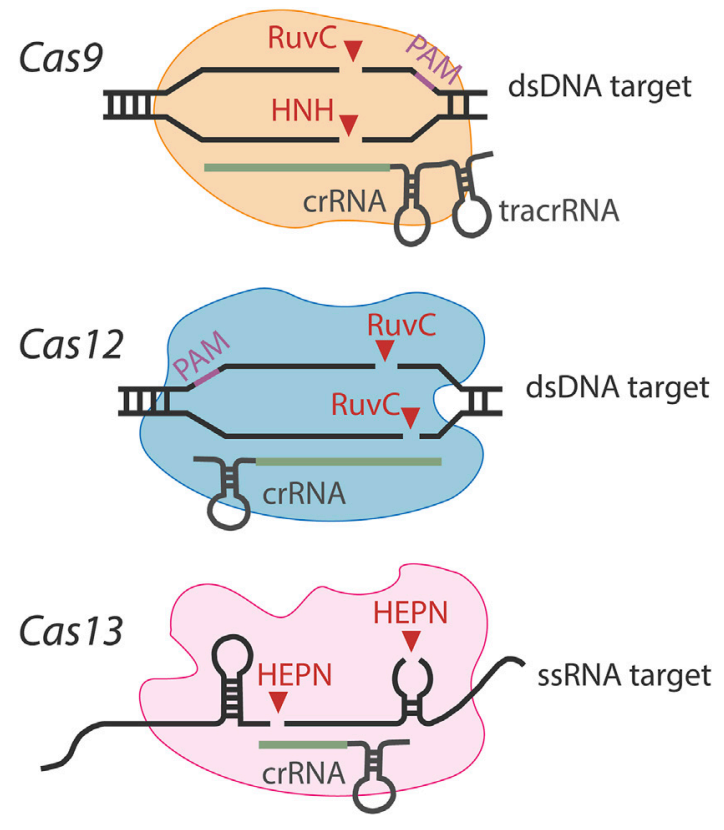

FIGURE 1 | Diagrams of Cas9, Cas12, and Cas13 nucleases.

named $\mathrm{C} 2 \mathrm{c} 2$, exhibits a collateral cleavage effect and only requires single-guide crRNA (Abudayyeh et al., 2016). After target binding, the HEPN catalytic site of Cas13a protein is activated, which subsequently cleaves both single-stranded target and collateral RNAs in a non-specific manner (Liu et al., 2017). Due to the "collateral effect," Cas13a can be promisingly used for nucleic acid detection, not only RNA but also dsDNA (Abudayyeh et al., 2017; Gootenberg et al., 2017; Wang et al., 2019). Currently, various Cas13 orthologs and variants were identified and characterized, including Cas13b (Smargon et al., 2017), Cas13d (Yan et al., 2018), Cas13X and Cas13Y (Xu C. et al., 2021), and Cas13bt (Kannan et al., 2021). In addition, the development of unrelated CRISPR nucleases, such as Csm6 combined with Cas13, showed a robust detection of RNA targets (Liu T. Y. et al., 2021).

Already, these Cas nucleases have been used for biosensing purposes, and different effectors show different nucleotide cleavage preferences (as shown in Figure 1), which can be selected according to specific applications. Major features of these most used Class II Cas nucleases are listed in Table1. Moreover, continued exploration is ongoing to uncover new functional orthologs and thoroughly investigate the targeting rules of Cas nucleases, leading to a substantial increase in the efficiency of target cleavage and high-target specificity.

\section{Consideration for Pre-Amplification Strategies}

Generally, pre-amplification steps were needed for samples with very low target concentration, which are difficult to distinguish from the background. Traditional PCR methods are highly sensitive and specific but demand costly equipment and 
TABLE 1 | Main features of most used Class I| Cas nucleases.

\begin{tabular}{|c|c|c|c|c|c|c|}
\hline Nucleases & Type & Nuclease domain & Guide type & Target & trans-Cleavage & PAM sequence \\
\hline Cas9 & Type ॥ & RuvC and $\mathrm{HNH}$ & crRNA and tracrRNA & dsDNA & - & G-rich \\
\hline Cas12 & Type V & RuvC-like & crRNA only/crRNA and tracrRNA & Mostly dsDNA & dsDNA/ssDNA & T-rich ${ }^{a}$ \\
\hline Cas13 & Type VI & HEPN & crRNA only & RNA & ssRNA & - \\
\hline
\end{tabular}

${ }^{a}$ T- or C-rich for Cas12f, also known as Cas14.

professional technicians, as well as the cost of essential turnover times for the thermal cycles. Thus, portable and isothermal amplification methods have been developed, including helicase-dependent amplification (HDA) (Vincent et al., 2004), recombinase polymerase amplification (RPA) (Piepenburg et al., 2006), and loop-mediated isothermal amplification (LAMP) (Tomita et al., 2008). HDA uses a DNA helicase to separate dsDNA and generate single-stranded templates for primer hybridization by single-stranded DNA (ssDNA)-binding proteins (SSBs), which was subsequently extended by DNA polymerases. In the whole process, the initial heat denaturation and subsequent thermocycling steps required by PCR can all be omitted, which provides a simple DNA amplification using low temperature from the beginning to the end of the reaction (Vincent et al., 2004). Despite its simplicity, the specificity of HAD cannot be comparable to PCR, which hampered the utilities. RPA mainly relies on three core enzymes: a recombinase, which is capable to pair oligonucleotide primers; an SSB, which binds to displaced strands of DNA to prevent the primers from being displaced; and strand-displacing polymerase (Piepenburg et al., 2006; Ortiz et al., 2022). Once the recombinase-driven primer targeting of homologous sequence in dsDNA is completed, DNA synthesis begins with the strand displacing polymerase, achieving exponential amplification. Similar to HAD, RPA steps can all be performed at a constant optimal temperature of $37^{\circ} \mathrm{C}$, which can also hold the activities at room temperature. A key obstacle for the use of RPA is the design for amplification primers and probes, which are usually longer than general PCR primers and need to be optimized by customers on their own conditions. LAMP uses a polymerase with high strand displacement activity and a replication activity and adopts two or three sets of primers to increase specificity and an additional pair of "loop primers" to accelerate the reaction (Tomita et al., 2008). In LAMP, the target sequence is amplified at a constant temperature of $60^{\circ} \mathrm{C}-65^{\circ} \mathrm{C}$, which can be easily obtained through a water bath.

Recently, novel isothermal amplification methods have been developed and proposed for sensitive detection. Rolling circle amplification (RCA) is initiated with circular template ligation, forming a long ssDNA or RNA, followed by primer-induced ssDNA elongation (Nosek et al., 2005; Ali et al., 2014). At constant temperature (room temperature to $65^{\circ} \mathrm{C}$ ), a large number of repeats complementary to the circular template can be produced. Additionally, RCA can be conducted in both free solutions and on top of immobilized targets (solid-phase amplification). With these advantages, CRISPR/Cas12a- or CRISPR/Cas13a-triggered RCA is developed as a highly sensitive and specific biosensor, for example, for the detection of microRNAs (Li D. et al., 2020; Tian et al., 2020; Qing et al., 2021; Zhou et al., 2021). Alternative isothermal amplification approaches, such as exponential amplification reaction (EXPAR) (Song J. et al., 2021; Wang et al., 2021b), hybridization chain reaction (HCR) (Xing et al., 2020; Kachwala et al., 2021; Liu et al., 2022), and strand displacement amplification (SDA) (Chen et al., 2021b; Deng et al., 2021; Gong et al., 2021) were combined with CRISPR systems for sensing pathogenic bacteria and viruses, gene mutation, and even proteins. Different characteristics of this isothermal amplification method were compared as listed in Table 2.

Additionally, different kinds of improvements have been tried to develop amplification-free CRISPR-based biosensors with the assistance of $\mathrm{Au}$ nanoparticles (Choi et al., 2021), gold nanoclusters (Liu P.-F. et al., 2021), nanopores (Nouri et al., 2020), and graphene field-effect transistor (Hajian et al., 2019). Another sensitive strategy without target amplification was reported by making use of both Cas13a and Cas14a (Sha et al., 2021). Alternatively, microfluidics techniques provided tremendous potentials for amplification-free platforms, including droplet manipulation and on-chip integration (Bruch et al., 2019a; Bruch et al., 2021; Yue et al., 2021b; Tian et al., 2021), which will be highlighted in the next section.

\section{POWERFUL SUPPORT BY MICROFLUIDICS PLATFORMS}

An ideal biosensor for molecular detection should be accurate, sensitive, and capable to give results rapidly (Goode et al., 2015). In this regard, minimal sample extraction and optimized preparation procedures will help to improve the detection sensitivity without increasing the cost of overall assay time. Microfluidics means precisely controlling and manipulating the behavior of fluids on a geometrically constrained small scale (Dong et al., 2019). The introduction of microfluidic technology can get rid of the demand for bulky instrumentation and offers ingenious storage for the required reagents, which attracts more and more interest for the development of biosensors with promising potential to transform into POC devices.

\section{Optimized Sample Preparation and Readout}

Most biosensors typically require a "two-step" assay with target amplification reactions and detection steps separately, which brings some drawbacks with the risk of carryover contamination (Yue et al., 2021a). To solve this problem, sophisticated assemblies were introduced, for example, pre- 
TABLE 2 | Comparison of isothermal amplification methods.

\begin{tabular}{|c|c|c|c|c|}
\hline Methods & Temperature $\left({ }^{\circ} \mathrm{C}\right)$ & Time & Involved proteins & Primers \\
\hline HDA & $\sim 37$ & $\sim 2 \mathrm{~h}$ & DNA helicase, SSB, DNA polymerase & 2 \\
\hline RPA & 25-42 (optimal 37) & $20 \min \sim 1 \mathrm{~h}$ & Recombinase, SSB, strand-displacing polymerase & 2 \\
\hline LAMP & $60-65$ & $20 \mathrm{~min} \sim 2 \mathrm{~h}$ & Strand-displacing DNA polymerase & $6-8$ \\
\hline RCA & Room temperature to 65 & $\sim 2 \mathrm{~h}$ & DNA polymerase & 4 \\
\hline EXPAR & $\sim 37$ & $2 \sim 3 \mathrm{~h}$ & DNA polymerase & 2 \\
\hline $\mathrm{HCR}$ & $\sim 37$ & $\sim 1 \mathrm{~h}$ & - & - \\
\hline SDA & $37-60$ & $0.5 \sim 1 \mathrm{~h}$ & Strand-displacing DNA polymerase, nicking endonuclease & 4 \\
\hline
\end{tabular}

Note. HDA, helicase-dependent amplification; RPA, recombinase polymerase amplification; LAMP, loop-mediated isothermal amplification; RCA, rolling circle amplification; EXPAR, exponential amplification reaction; HCR, hybridization chain reaction; SDA, strand displacement amplification; SSB, single-stranded DNA-binding protein.

embedding CRISPR-Cas12a reagents on the inner wall of the tube cap and then mixing with amplicon solution by hand shaking (Chen et al., 2020c). Another group carried out RPA reaction and CRISPR-Cas12a detection in spatially separated but connected phases in one pot (Yin et al., 2020). Similarly, Wu et al. used an oil-sealed polypropylene (PP) bag with three chambers for washing and amplification/detection (Wu et al., 2021a).

Microfluidic chips hold promises to streamline analysis steps and integrate them in closed microchannels separately, with the capability of reducing reagent consumption and increasing detection throughput (Ahmadi et al., 2020). For example, droplet microfluidics enables to confine the Cas catalysis in cell-like-sized reactors via an ultralocalized droplet, enhancing the local concentrations of target and reporter simultaneously to obtain excellent specificity and sensitivity (Yue et al., 2021b; Tian et al., 2021). Lab-on-a-chip can also be introduced, which implements a miniaturized system, spatially separating multiple immobilization areas within a single channel (Bruch et al., 2019a; Bruch et al., 2021). Taken together, sealing up spatially separately helps to increase the stability for long-term storage, and the automated process makes it more convenient to extend the applications with a reduced cost of operation time.

\section{Development for Automated POC Devices}

According to the WHO guidelines, POC testing needs to be affordable, sensitive, specific, user-friendly, robust and rapid, equipment-free, and deliverable to all people who need the test (ASSURED) (van Dongen et al., 2020). Taking these into account, microfluidics techniques promisingly offer simplified approaches (sample-in result-out) for biosensing automatedly with high throughput. Chen et al. integrated the CRISPR/Cas12a system and recombinase-aided amplification in a centrifugal microfluidic device, avoiding the catalysis of Cas12a to the template DNA. This Cas12a-assisted straightforward microfluidic equipment for analysis of nucleic acid, termed CASMEAN, was reported to enable nucleic acid detection within $1.5 \mathrm{~h}$ (Chen et al., 2020b). Wu et al. developed a reversible valve-assisted chip to integrate CRISPR/Cas12a system and LAMP into a single chip, which has three reversible rotary valves and can be rotated relying on the direction-dependent Coriolis pseudo force. Their POC device achieves a limit of detection (LoD) of 30 copies/reaction for the detection of Vibrio parahaemolyticus (Wu et al., 2021b). Chen et al. proposed a POC biochip with preloaded CRISPR/Cas12a reagents for processing automatedly, capable to detect the genotypes within $20 \mathrm{~min}$ (Chen Y. et al., 2021). Taken together, microfluidics strategies facilitate biosensors developing to POC device development.

\section{APPLICATIONS OF CRISPR-BASED BIOSENSING TECHNIQUES}

Nowadays, CRISPR systems have been established as powerful biosensing tools for detecting various targets (Li et al., 2019b; Bao et al., 2021; Kaminski et al., 2021). Several developed CRISPRbased biosensors were characterized in Table 3. Their main application in the sensing of a wide range of molecular targets was highlighted as follows.

\section{Diagnosis of Pathogen Infections SARS-CoV-2}

The main focus of CRISPR-based biosensing techniques has been the diagnostics of pathogen infection benefits from their DNAand RNA-targeting nucleases (Escalona-Noguero et al., 2021). Amid the ongoing pandemic of COVID-19, enormous efforts have been paid for the detection of SARS-CoV-2 (Nouri et al., 2021). SHERLOCK was first developed using Cas13a with RPA amplification to detect Zika and Dengue virus and to identify human DNA, exhibiting similar levels of sensitivity to RT-qPCR (capable of single-molecular detection) (Gootenberg et al., 2017). Subsequently, it was advanced to SHERLOCK version 2 (SHERLOCKv2) integrated with multiplexed orthogonal CRISPR enzymes to increase signal sensitivity and portable lateral-flow readout (Gootenberg et al., 2018). SHERLOCK was further advanced with HUDSON (heating unextracted diagnostic samples to obliterate nucleases) for viral detection directly from bodily fluids, enabling instrument-free virus detection directly from patient samples within less than $2 \mathrm{~h}$ (Myhrvold et al., 2018). The step-by-step instructions for SHERLOCK assays were then published, demonstrating the use of Cas13 or Cas12, combination with isothermal preamplification, and the detection through fluorescence and colorimetric readouts (Kellner et al., 2019). As the outbreak of SARS-CoV-2, it was streamlined into SHERLOCK testing in one pot (STOP) combined with simplified extraction of viral RNA, which can be performed for the detection of SARS-CoV-2 at a single temperature in less than $1 \mathrm{~h}$ and with minimal equipment 
TABLE 3 | Major characteristic of several developed CRISPR-based biosensors for nucleic acid detection.

\begin{tabular}{|c|c|c|c|c|c|c|c|c|}
\hline Name & Cas systems & Target & Amplification & Readout & Sensitivity & Specificity & Time & Ref \\
\hline SHERLOCK & Cas13a & $\begin{array}{l}\text { DNA } \\
\text { RNA }\end{array}$ & RPA & Fluorescent & $\mathrm{aM}$ & $1 \mathrm{nt}$ & $<2 \mathrm{~h}$ & $\begin{array}{l}\text { Gootenberg et al., 2017; } \\
\text { Kellner et al., } 2019\end{array}$ \\
\hline SHERLOCKV2 & $\begin{array}{l}\text { PsmCas13b, LwaCas13a, } \\
\text { CcaCas13b, AsCas12a }\end{array}$ & $\begin{array}{l}\text { DNA } \\
\text { RNA }\end{array}$ & RPA & $\begin{array}{l}\text { Fluorescent/ } \\
\text { colorimetric }\end{array}$ & $\mathrm{zM}$ & $1 \mathrm{nt}$ & $0.5-3 h$ & Gootenberg et al. (2018) \\
\hline $\begin{array}{l}\text { SHERLOCK + } \\
\text { HUDSON }\end{array}$ & Cas13a & $\begin{array}{l}\text { DNA } \\
\text { RNA }\end{array}$ & RPA & Fluorescent & $\mathrm{aM}$ & $1 \mathrm{nt}$ & $<2 \mathrm{~h}$ & Myhrvold et al. (2018) \\
\hline DETECTR & Cas12a & DNA & RPA & Fluorescent & $\mathrm{aM}$ & $6 \mathrm{nt}$ & $\sim 2 \mathrm{~h}$ & $\begin{array}{l}\text { Broughton et al. (2020); } \\
\text { Chen et al. (2018) }\end{array}$ \\
\hline HOLMES & Cas12a & $\begin{array}{l}\text { DNA } \\
\text { RNA }\end{array}$ & PCR & Fluorescent & $\mathrm{aM}$ & $1 \mathrm{nt}$ & $\sim 1 \mathrm{~h}$ & Li et al. (2018) \\
\hline HOLMESV2 & Cas12b & $\begin{array}{l}\text { DNA } \\
\text { RNA }\end{array}$ & LAMP/PCR & Fluorescent & $\mathrm{aM}$ & $1 \mathrm{nt}$ & $\sim 1 \mathrm{~h}$ & Li et al. (2019a) \\
\hline SHINE & Cas13 & RNA & RPA & Colorimetric & $\mathrm{aM}$ & - & $50 \mathrm{~min}$ & Arizti-Sanz et al. (2020) \\
\hline
\end{tabular}

Note. RPA, recombinase polymerase amplification; LAMP, loop-mediated isothermal amplification.

(Joung et al., 2020a; Joung et al., 2020b). SHERLOCK-based assay for SARS-CoV-2 detection has been tested in a validated clinical cohort including 154 nasopharyngeal and throat swab samples and 380 SARS-CoV-2-negative preoperative samples (Patchsung et al., 2020). Results showed that it reached a detection limit of 42 RNA copies per reaction, with $100 \%$ sensitivity for fluorescence readout, 97\% sensitivity for lateral-flow readout, and both $100 \%$ specificity. DETECTR provided an attomolar sensitivity for DNA detection using Cas12a and was optimized to detect SARS-CoV-2 via its $\mathrm{N}$ (nucleoprotein) and $\mathrm{E}$ (envelop small membrane protein) genes (Chen et al., 2018; Broughton et al., 2020). DETECTR can be performed in less than $40 \mathrm{~min}$ from respiratory swab RNA extracts using lateral flow readout and be validated by 36 patients with COVID-19 infection and 42 patients with other viral respiratory infections with $95 \%$ positive predictive agreement and $100 \%$ negative predictive agreement with RT-qPCR assay from the US Centers for Disease Control and Prevention (Broughton et al., 2020). Another Cas13a-based assay, Streamlined Highlighting of Infections to Navigate Epidemics (SHINE), was developed to detect SARS-CoV-2 RNA from unextracted samples by optimizing RPA-based preamplification and Cas13-based detection into a single step and improve HUDSON to accelerate viral extraction in nasopharyngeal swabs and saliva samples (Arizti-Sanz et al., 2020). The validation from 50 nasopharyngeal patient samples demonstrated that SHINE has $90 \%$ sensitivity and $100 \%$ specificity against RT-qPCR with a sample-to-answer time of $50 \mathrm{~min}$.

To balance the sensitivity, specificity, and test availability, a variety of strategies have been tried to improve the detection of SARS-CoV-2. For example, DNA-modified gold nanoparticles (AuNPs) were utilized for a universal colorimetric readout according to the change in the surface plasmon resonance, which can be monitored by UV-vis absorbance spectroscopy facially and observed by the naked eye (Zhang W. S. et al., 2021). An alternative is assisted with magnetic AuNP probe colorimetric assay, which is not dependent on sophisticated instruments and can be potentially adopted under poor conditions (Jiang et al., 2021). Different amplification strategies were also explored to couple with CRISPR-based SARS-CoV-2 biosensing, such as
HCR amplification, which was reported in an evanescent wave fluorescence biosensing platform providing an attomolar detection level towards SARS-CoV-2 within $1 \mathrm{~h}$ (Yang et al., 2021), and multiple cross displacement amplification (MCDA), which conducts reverse transcription MCDA reaction when CRISPR-Cas12a/CrRNA complex recognizes the predefined target sequences and subsequently degrades a single-strand DNA to confirm the target detection (Zhu et al., 2021). A major direction of biosensing platforms is to develop POC devices. Hence, portable approaches were taken into mind. An attempt was made to adopt the available personal glucose meter to readout for quantitative detection of SARS-CoV-2 via converting the virus signal to a glucose-producing reaction (Huang et al., 2021). Already benefitting from an elegant detection mechanism, fast assay time, and low reaction temperature, these assays can be further advanced via integration with powerful, digital-based detection. A coined digitization-enhanced CRISPR/Cas-assisted one-pot virus detection (deCOViD) was reported to achieve qualitative detection in $<15 \mathrm{~min}$ and quantitative detection in $30 \mathrm{~min}$ with down to 1 genome equivalent (GE) per $\mu$ l of SARS-CoV2 RNA and 20 GE per $\mu$ l of heat-inactivated SARS-CoV-2 (Park et al., 2021). A digital warm-start CRISPR (dWS-CRISPR) assay showed a detection down to five copies/ $\mu$ SARS-CoV-2 RNA, as well as the capability to directly detect SARS-CoV-2 in heattreated saliva samples without RNA extraction (Ding X. et al., 2021). These digital methods facilitate accurate, sensitive, and reliable CRISPR assays into POC devices, with a high signal-tobackground ratio and broad dynamic range. In addition, preventing amplicon-formed aerosol contamination is also an important process. One group pre-added reagent on the inner wall of the tube lid, which were then hand-shaken to make them flow into the tube and mix with amplicon solution, which could be processed within $40 \mathrm{~min}$ and reach a sensitivity of 20 copies RNA of SARS-CoV-2 (Chen et al., 2020c). A more portable platform incorporated sample preparation with the facile magnetic-based operation of nucleic acid concentration and transport and streamlined into a compact palm-sized thermoplastic cartridge functioning in a fully integrated and autonomous way, which can detect $1 \mathrm{GE} / \mu \mathrm{l}$ SARS-CoV-2 RNA 
from $100 \mu \mathrm{l}$ of sample in less than $30 \mathrm{~min}$ (Chen F.-E. et al., 2021). This kind of integration of microfluidic platforms streamlined sample preparation procedures fully into autonomous and portable devices, opening a new avenue to facilitate POC methods for SARS-CoV-2 detection (Mu et al., 2020; Ramachandran et al., 2020; Basiri et al., 2021).

\section{Other Infectious Bacteria and Viruses}

CRISPR-based methods have been widely developed for the detection of infectious pathogens. Detection of HIV-1 termed as Solid-State CRISPR-Cas12a-Assisted Nanopores (SCAN) can recognize target DNA concentrations at least to $10 \mathrm{nM}$ within $1 \mathrm{~h}$, without the requirement of pre-amplification steps (Nouri et al., 2020). A report detecting HBV based on DETECTR showed an LoD of $1 \mathrm{copy} / \mu \mathrm{l}$ within $13 \mathrm{~min}$ using fluorescent readout; however, the LoD of lateral flow test strip technique costing 20 min was not shown (Ding R. et al., 2021). Utilizing lateral flow, a Cas12a-based biosensor was designed for the detection of Epstein-Barr virus (EBV), achieving a sensitivity of $7.1 \times$ $10^{-14} \mathrm{~mol} / \mathrm{L}$ (approximately 42,000 copies per $\mu \mathrm{l}$ ) (Yuan et al., 2020). Another Cas12a-based biosensor using a dynamic aqueous multiphase reaction system was introduced to detect human papillomavirus (HPV) with sensitivities of 10-100 copies in less than $1 \mathrm{~h}$ (Yin et al., 2020). Supported by automated microfluidic mixing, an approach for Ebola virus detection was established using Cas13a and achieved an LoD of $20 \mathrm{pfu} /$ $\mathrm{ml}\left(5.45 \times 10^{7}\right.$ copies $\left./ \mathrm{ml}\right)$ of purified Ebola RNA within 5 min (Qin et al., 2019).

Cas12a-based biosensing was also developed for the detection of a variety of pathogenic microorganisms, such as Listeria monocytogenes (Li F. et al., 2021), Cryptosporidium parvum (Yu et al., 2021), Salmonella (Ma et al., 2021), Helicobacter pylori (Qiu et al., 2021), Yersinia pestis (You et al., 2021), E. coli, and Staphylococcus aureus (Bonini et al., 2021). Coupling with a reversible valve-assisted chip, sample preparation, Cas12a reactions, and LAMP was integrated and controlled precisely to perform the detection of $V$. parahaemolyticus, achieving an LoD of 30 copies/reaction within $50 \mathrm{~min}$ ( $\mathrm{Wu}$ et al., 2021b). Cas14a (also known as Cas12f1) was exploited for the detection of pathogenic bacteria combined with a universal nucleic acid magneto-DNA nanoparticle system, which can achieve $1 \mathrm{cfu} / \mathrm{ml}$ or $1 \mathrm{aM}$ sensitivity (Song F. et al., 2021). The Cas14a1-mediated platform was also reported for the detections of pathogens benefitting from its small size and independence of PAM (Ge et al., 2021). Further development by introducing novel aptamer, a Cas13a assay enables mix-and-read detection of viable pathogenic bacteria without the need of reverse transcription, nucleic acid amplification, and chemical labeling, which obtained an LoD of 10 CFU for Bacillus cereus (Zhang T. et al., 2021).

\section{Detection of Non-Infectious Diseases}

CRISPR-based biosensors also showed promising potential for the detection of non-infectious human diseases, such as cancer, based on the features with disease-related gene mutations, singlenucleotide polymorphism, DNA methylation, and so on (Aman et al., 2020; Li B. et al., 2021; Wang et al., 2021c; Chen Y. et al.,
2021; Sheng et al., 2021). For example, a Cas12a-based biosensor showed sensitive detection of gene-PIK $3 \mathrm{CA}^{\mathrm{H} 1047 \mathrm{R}}$ mutation low at $0.001 \%$, which has great potential to predict early-stage breast cancer (Deng et al., 2021). A Cas12a-based transcription factor detection method showed an LoD of 0.2 pM for NF-kappaB p50 subunit from cancer cell samples, which can be further applied for physical dysfunction monitoring and drug screening (Li B. et al., 2021). Recent work introduced a hairpin probe to preserve the analytical fidelity and developed a CRISPR/Cas9-triggered hairpin probe-mediated biosensing method, termed the CHP system, specifically initiating double isothermal amplifications when Cas9-mediated cleavage occurs and the hairpin probe recognizes the original sequences (Wang M. et al., 2021). This system has an LoD at the attomole level to quantify DNA targets and identify single-nucleotide variations with allelic fractions down to $0.01 \%-0.1 \%$.

In addition to the genome profile, other disease-related nucleic acids were chosen as detection targets. MicroRNAs (miRNAs), which have been reported to be related to many biological processes, are regarded as disease biomarkers. Hence, Cas12a or Cas13a systems have been widely used for the profiling of microRNAs, with or without assisting pre-amplification, and can highly reach an $\mathrm{fM}$ sensitivity and single-base specificity (Tian et al., 2020; Cui et al., 2021; Sha et al., 2021; Zhou et al., 2021). Circulating tumor DNA (ctDNA) represented another type of credible biomarkers for clinical diagnosis and prognosis. In this regard, a CRISPR/Cas9 biosensor based on a 3D graphene/ AuPtPd nanoflower was developed to trigger entropy-driven strand displacement reaction for ctDNA detection (Chen et al., 2020a).

\section{Testing in Animal Husbandry, Agriculture, and Forestry}

In socioeconomic terms, CRISPR-based biosensing techniques were also developed to satisfy the demand from animal husbandry, agriculture, and forestry. For example, a Cas12abased lateral flow biosensor combined with PCR amplification was used for the detection of the African swine fever virus (ASFV), achieving a sensitivity of $2.5 \times 10^{-15} \mathrm{M}$ within $2 \mathrm{~h}$ from swine blood (Wu et al., 2020). Another Cas12a-based reversible valve-assisted chip was established for the rapid detection of $V$. parahaemolyticus for the seafood test, with an LoD of 30 copies/reaction by using $600 \mu \mathrm{l}$ of samples (Wu et al., 2021b). In the field of agriculture and forestry, the Cas9 system combined with AuNPs has been developed to identify plantassociated disease through the detection of Phytophthora infestans (Chang et al., 2019). Cas12a-based biosensors were developed for the detection of plant DNA virus (Mahas et al., 2021) and the nopaline synthase terminator in genetically modified crops (Huang et al., 2020).

\section{Sensing for Non-Nucleic Acid Targets}

As shown above, robust development of CRISPR-based biosensors was applied to detect the nucleic acid targets. Combined with a microfluidic chip, the CRISPR/Cas9 system can be developed for rapid and efficient kinase screening 


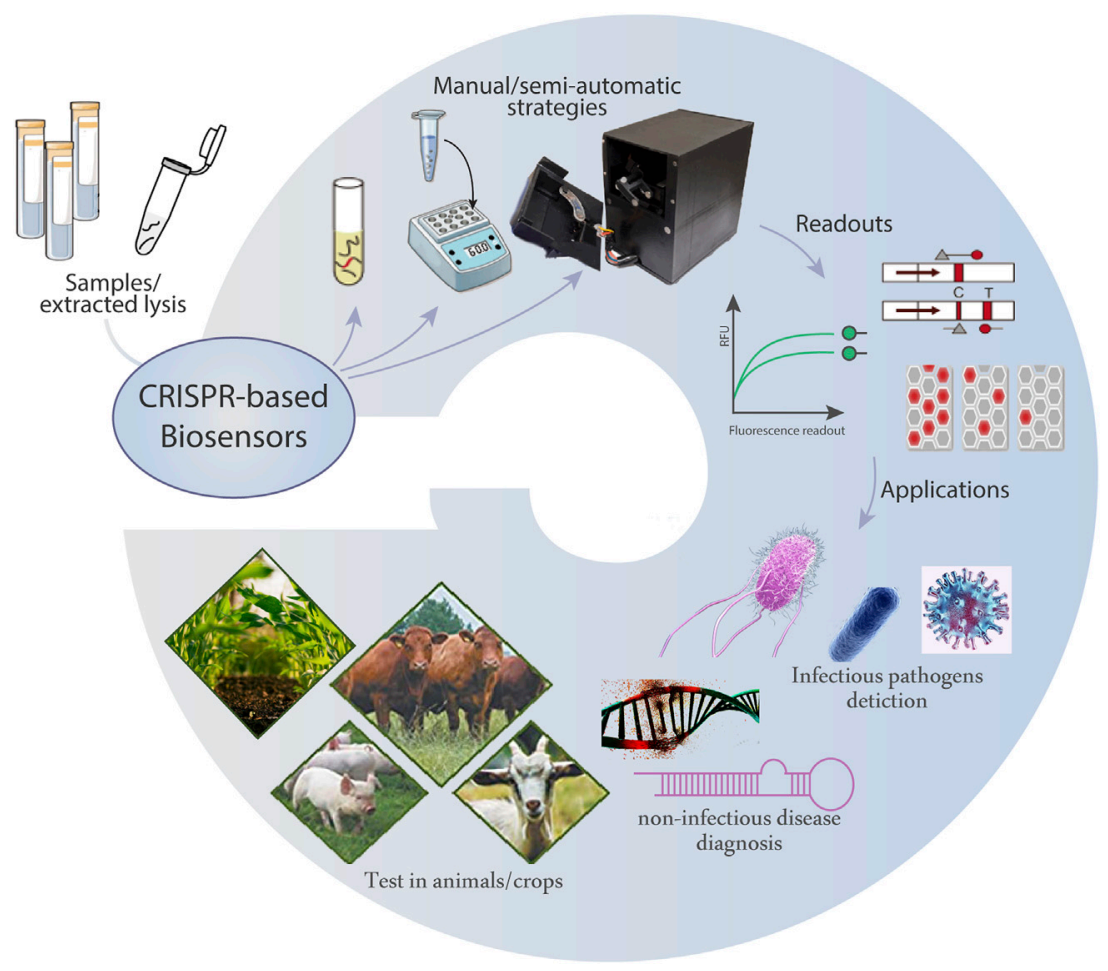

FIGURE 2 | Illustration of the wide applications of CRISPR-based biosensors.

and further to separate cells according to different deformability, with flexible cells flowing out and stiff cells remaining trapped (Han et al., 2016). Recently, immunoassays based on CRISPR/Cas systems for the sensitive and rapid detection of protein targets were also explored, which is akin to the traditional ELISA (Zhao Q. et al., 2021; Li H. et al., 2021). Li et al. designed a series of aptamer-flanked activator DNA strands to correlate non-nucleic acid analytes with the CRISPR/Cas12a system, enabling an ultrasensitive detection ( $\mathrm{Li} \mathrm{H}$. et al., 2021). Zhao et al. employed DNA-AuNPs to establish the signal transduction between trans-cleavage of CRISPR/Cas12a and protein analytes and showed a quantitative level of attomolar, 1,000-fold more sensitive and 15 -fold wider detection range than traditional ELISA (Zhao Q. et al., 2021). CRISPR-based electrochemiluminescence biosensors have been explored for the detection of enzymes like polynucleotide kinase/ phosphatase (Wang et al., 2020) and alkaline phosphatase (Wang et al., 2021d), and signal factors like endogenous chemokine (White et al., 2021) and sialic acid-binding immunoglobulin-like lectins (Zhang K. et al., 2021). Similar to aptamers, DNAzymes or DNA ligations were also designed to introduce CRISPR/Cas12a biosensor for non-nucleic acid targets, for example, testing melamine (Qiao et al., 2021), metal ion $\mathrm{Na}^{+}$(Li C.-Y. et al., 2020), $\mathrm{NAD}^{+}$, and ATP (Zhao J. et al., 2021; Niu et al., 2021). Additionally, with the adoption of AuNP, the applications of CRISPR-driven biosensors were potentially extended, such as the ultrasensitive detection of mycotoxins including aflatoxin M1 (Abnous et al., 2021), assessment for telomerase activity by analyzing telomeric repeat DNA, and internal control products (Cheng et al., 2021). Furthermore, CRISPR/Cas12a-based biosensors can monitor protein/small molecule interactions, like streptavidin/ biotin and anti-digoxigenin/digoxigenin (Kim et al., 2021).

\section{CONCLUSION AND PERSPECTIVES}

The CRISPR-based biosensors provide low-cost and easily scalable tools for the detection of various targets with high sensitivity and specificity. The combinations with microfluidic techniques powerfully integrate multiple steps of sample preparation, Cas-mediated catalysis, target amplification, and readout. Currently, these biosensors have been applied in nucleic acid-based diagnostics, protein tests, metal ion monitoring, and protein/small molecule interactions screening, which are promising in the fields of healthcare, animal husbandry, agriculture, and forestry (Figure 2).

Additionally, these platforms still face challenges in the multiplex detection, due to the limited signal reporting strategies and possible cross-reactions, which would be introduced with the interference between recognition molecules and various analytes, and exacerbated by the complexity of clinical samples (Bruch et al., 2019b; Li 
et al., 2019c). Introducing various labels, including fluorophore dyes, enzymes, or beads, and effectively combining different strategies will be promising directions. SHERLOCKv2 made four-channel single-reaction multiplexing of Cas12a and Cas13, increasing the signal sensitivity by introducing an auxiliary CRISPR-associated enzyme Csm6 (Gootenberg et al., 2018). Another successful attempt used an orthogonal DNA/RNA collateral cleavage by Cas12a and Cas13a assay in a single tube simultaneously, which specifically illuminated two spectral differentiated DNA and RNA probes, respectively, exhibiting 100\% sensitivity and specificity for clinical samples analysis (32 swab specimens for SARS-CoV-2 and 35 ASFV-suspected swine blood samples) (Tian et al., 2022). Furthermore, thinking of machine learning approaches and the internet for wireless signal transmission over the cloud supports futuristic decision making (Ibrahim et al., 2020).

\section{REFERENCES}

Abnous, K., Danesh, N. M., Ramezani, M., Alibolandi, M., Nameghi, M. A., Zavvar, T. S., et al. (2021). A Novel Colorimetric Aptasensor for Ultrasensitive Detection of Aflatoxin M1 Based on the Combination of CRISPR-Cas12a, Rolling circle Amplification and Catalytic Activity of Gold Nanoparticles. Analytica Chim. Acta 1165, 338549. doi:10.1016/j.aca.2021.338549

Abudayyeh, O. O., Gootenberg, J. S., Essletzbichler, P., Han, S., Joung, J., Belanto, J. J., et al. (2017). RNA Targeting with CRISPR-Cas13. Nature 550, 280-284. doi:10.1038/nature24049

Abudayyeh, O. O., Gootenberg, J. S., Konermann, S., Joung, J., Slaymaker, I. M., Cox, D. B. T., et al. (2016). C2c2 Is a Single-Component Programmable RNAGuided RNA-Targeting CRISPR Effector. Science 353, aaf5573. doi:10.1126/ science.aaf5573

Ahmadi, F., Quach, A. B. V., and Shih, S. C. C. (2020). Is Microfluidics the "assembly Line" for CRISPR-Cas9 Gene-Editing? Biomicrofluidics 14, 061301. doi:10.1063/5.0029846

Ali, M. M., Li, F., Zhang, Z., Zhang, K., Kang, D.-K., Ankrum, J. A., et al. (2014). Rolling circle Amplification: a Versatile Tool for Chemical Biology, Materials Science and Medicine. Chem. Soc. Rev. 43, 3324-3341. doi:10.1039/c3cs60439j

Aman, R., Mahas, A., and Mahfouz, M. (2020). Nucleic Acid Detection Using CRISPR/Cas Biosensing Technologies. ACS Synth. Biol. 9, 1226-1233. doi:10. 1021/acssynbio.9b00507

Anzalone, A. V., Randolph, P. B., Davis, J. R., Sousa, A. A., Koblan, L. W., Levy, J. M., et al. (2019). Search-and-replace Genome Editing without Double-Strand Breaks or Donor DNA. Nature 576, 149-157. doi:10.1038/s41586-019-1711-4

Arizti-Sanz, J., Freije, C. A., Stanton, A. C., Petros, B. A., Boehm, C. K., Siddiqui, S., et al. (2020). Streamlined Inactivation, Amplification, and Cas13-Based Detection of SARS-CoV-2. Nat. Commun. 11, 5921. doi:10.1038/s41467020-19097-x

Bao, M., Chen, Q., Xu, Z., Jensen, E. C., Liu, C., Waitkus, J. T., et al. (2021). Challenges and Opportunities for Clustered Regularly Interspaced Short Palindromic Repeats Based Molecular Biosensing. ACS Sens. 6, 2497-2522. doi:10.1021/acssensors.1c00530

Basiri, A., Heidari, A., Nadi, M. F., Fallahy, M. T. P., Nezamabadi, S. S., Sedighi, M., et al. (2021). Microfluidic Devices for Detection of RNA Viruses. Rev. Med. Virol. 31, 1-11. doi:10.1002/rmv.2154

Bigelyte, G., Young, J. K., Karvelis, T., Budre, K., Zedaveinyte, R., Djukanovic, V., et al. (2021). Miniature Type V-F CRISPR-Cas Nucleases Enable Targeted DNA Modification in Cells. Nat. Commun. 12, 6191. doi:10.1038/s41467-02126469-4

Bonini, A., Poma, N., Vivaldi, F., Biagini, D., Bottai, D., Tavanti, A., et al. (2021). A Label-free Impedance Biosensing Assay Based on CRISPR/Cas12a Collateral Activity for Bacterial DNA Detection. J. Pharm. Biomed. Anal. 204, 114268. doi:10.1016/j.jpba.2021.114268

\section{AUTHOR CONTRIBUTIONS}

All the authors conducted the bibliography retrieval and data collection. $\mathrm{BC}$ and $\mathrm{YL}$ organized the figures and tables. $\mathrm{BC}$ wrote the manuscript. XY and FX checked the whole paper.

\section{FUNDING}

This work was supported by the National Natural Science Foundation of China (81802325 and 61874099); Science and Technology Research Program of Henan Province (202102310209); Medical Science and Technology Project of Henan Province (2018020045); China Postdoctoral Science Foundation (2018M642796); Natural Science Foundation of Henan Province (202300410398); and Key Project of scientific research Foundation for Colleges and Universities in Henan Province (20A320051 and 20B320025).

Broughton, J. P., Deng, X., Yu, G., Fasching, C. L., Servellita, V., Singh, J., et al. (2020). CRISPR-Cas12-based Detection of SARS-CoV-2. Nat. Biotechnol. 38 870-874. doi:10.1038/s41587-020-0513-4

Bruch, R., Baaske, J., Chatelle, C., Meirich, M., Madlener, S., Weber, W., et al. (2019a). CRISPR/Cas13a-Powered Electrochemical Microfluidic Biosensor for Nucleic Acid Amplification-Free miRNA Diagnostics. Adv. Mater. 31, 1905311. doi:10.1002/adma.201905311

Bruch, R., Johnston, M., Kling, A., Mattmüller, T., Baaske, J., Partel, S., et al. (2021). CRISPR-powered Electrochemical Microfluidic Multiplexed Biosensor for Target Amplification-free miRNA Diagnostics. Biosens. Bioelectron. 177, 112887. doi:10.1016/j.bios.2020.112887

Bruch, R., Urban, G. A., and Dincer, C. (2019b). CRISPR/Cas Powered Multiplexed Biosensing. Trends Biotechnology 37, 791-792. doi:10.1016/j.tibtech.2019. 04.005

Chang, W., Liu, W., Liu, Y., Zhan, F., Chen, H., Lei, H., et al. (2019). Colorimetric Detection of Nucleic Acid Sequences in Plant Pathogens Based on CRISPR/ Cas9 Triggered Signal Amplification. Microchim Acta 186, 243. doi:10.1007/ s00604-019-3348-2

Chen, F.-E., Lee, P.-W., Trick, A. Y., Park, J. S., Chen, L., Shah, K., et al. (2021a). Point-of-care CRISPR-Cas-Assisted SARS-CoV-2 Detection in an Automated and Portable Droplet Magnetofluidic Device. Biosens. Bioelectron. 190, 113390. doi:10.1016/j.bios.2021.113390

Chen, J. S., Ma, E., Harrington, L. B., Da Costa, M., Tian, X., Palefsky, J. M., et al. (2018). CRISPR-Cas12a Target Binding Unleashes Indiscriminate SingleStranded DNase Activity. Science 360, 436-439. doi:10.1126/science.aar6245

Chen, M., Wu, D., Tu, S., Yang, C., Chen, D., and Xu, Y. (2021a). CRISPR/Cas9 Cleavage Triggered ESDR for Circulating Tumor DNA Detection Based on a 3D graphene/AuPtPd Nanoflower Biosensor. Biosens. Bioelectron. 173, 112821. doi:10.1016/j.bios.2020.112821

Chen, X., Deng, Y., Cao, G., Xiong, Y., Huo, D., and Hou, C. (2021b). Ultrasensitive MicroRNA-21 Detection Based on Multiple Cascaded Strand Displacement Amplification and CRISPR/Cpf1 (MC-SDA/CRISPR/Cpf1). Chem. Commun. 57, 6129-6132. doi:10.1039/d1cc01938d

Chen, X., Tan, Y., Wang, S., Wu, X., Liu, R., Yang, X., et al. (2021c). A CRISPRCas12b-Based Platform for Ultrasensitive, Rapid, and Highly Specific Detection of Hepatitis B Virus Genotypes B and C in Clinical Application. Front. Bioeng. Biotechnol. 9, 743322. doi:10.3389/fbioe.2021.743322

Chen, Y., Mei, Y., and Jiang, X. (2021d). Universal and High-Fidelity DNA Single Nucleotide Polymorphism Detection Based on a CRISPR/Cas12a Biochip. Chem. Sci. 12, 4455-4462. doi:10.1039/d0sc05717g

Chen, Y., Mei, Y., Zhao, X., and Jiang, X. (2020b). Reagents-Loaded, Automated Assay that Integrates Recombinase-Aided Amplification and Cas12a Nucleic Acid Detection for a Point-of-Care Test. Anal. Chem. 92, 14846-14852. doi:10. 1021/acs.analchem.0c03883

Chen, Y., Shi, Y., Chen, Y., Yang, Z., Wu, H., Zhou, Z., et al. (2020c). Contamination-free Visual Detection of SARS-CoV-2 with CRISPR/Cas12a: 
A Promising Method in the point-of-care Detection. Biosens. Bioelectron. 169, 112642. doi:10.1016/j.bios.2020.112642

Cheng, M., Xiong, E., Tian, T., Zhu, D., Ju, H.-q., and Zhou, X. (2021). A CRISPRDriven Colorimetric Code Platform for Highly Accurate Telomerase Activity Assay. Biosens. Bioelectron. 172, 112749. doi:10.1016/j.bios.2020.112749

Choi, J.-H., Lim, J., Shin, M., Paek, S.-H., and Choi, J.-W. (2021). CRISPR-Cas12aBased Nucleic Acid Amplification-free DNA Biosensor via Au NanoparticleAssisted Metal-Enhanced Fluorescence and Colorimetric Analysis. Nano Lett. 21, 693-699. doi:10.1021/acs.nanolett.0c04303

Collias, D., and Biesel, C. L. (2021). CRISPR Technologies and the Search for the PAM-Free Nuclease. Nat. Commun. 12, 555. doi:10.1038/s41467-020-20633-y

Cong, L., Ran, F. A., Cox, D., Lin, S., Barretto, R., Habib, N., et al. (2013). Multiplex Genome Engineering Using CRISPR/Cas Systems. Science 339, 819-823. doi:10. 1126/science.1231143

Cui, Y., Fan, S., Yuan, Z., Song, M., Hu, J., Qian, D., et al. (2021). Ultrasensitive Electrochemical Assay for microRNA-21 Based on CRISPR/Cas13a-assisted Catalytic Hairpin Assembly. Talanta 224, 121878. doi:10.1016/j.talanta.2020. 121878

Deng, Y., Cao, G., Chen, X., Yang, M., Huo, D., and Hou, C. (2021). Ultrasensitive Detection of Gene-Pik3cah1047r Mutation Based on Cascaded Strand Displacement Amplification and Trans-cleavage Ability of CRISPR/Cas12a. Talanta 232, 122415. doi:10.1016/j.talanta.2021.122415

Ding, R., Long, J., Yuan, M., Zheng, X., Shen, Y., Jin, Y., et al. (2021a). CRISPR/ Cas12-Based Ultra-sensitive and Specific Point-of-Care Detection of HBV. Ijms 22, 4842. doi:10.3390/ijms22094842

Ding, X., Yin, K., Li, Z., Sfeir, M. M., and Liu, C. (2021b). Sensitive Quantitative Detection of SARS-CoV-2 in Clinical Samples Using Digital Warm-Start CRISPR Assay. Biosens. Bioelectron. 184, 113218. doi:10.1016/j.bios.2021. 113218

Dong, R., Liu, Y., Mou, L., Deng, J., and Jiang, X. (2019). Microfluidics-Based Biomaterials and Biodevices. Adv. Mater. 31, 1805033. doi:10.1002/adma. 201805033

Donohoue, P. D., Pacesa, M., Lau, E., Vidal, B., Irby, M. J., Nyer, D. B., et al. (2021). Conformational Control of Cas9 by CRISPR Hybrid RNA-DNA Guides Mitigates Off-Target Activity in T Cells. Mol. Cel 81, 3637-3649. e3635. doi:10.1016/j.molcel.2021.07.035

Escalona-Noguero, C., López-Valls, M., and Sot, B. (2021). CRISPR/Cas Technology as a Promising Weapon to Combat Viral Infections. Bioessays 43, 2000315. doi:10.1002/bies.202000315

Fu, Y., Sander, J. D., Reyon, D., Cascio, V. M., and Joung, J. K. (2014). Improving CRISPR-Cas Nuclease Specificity Using Truncated Guide RNAs. Nat. Biotechnol. 32, 279-284. doi:10.1038/nbt.2808

Gasiunas, G., Barrangou, R., Horvath, P., and Siksnys, V. (2012). Cas9-crRNA Ribonucleoprotein Complex Mediates Specific DNA Cleavage for Adaptive Immunity in Bacteria. Proc. Natl. Acad. Sci. 109, E2579-E2586. doi:10.1073/ pnas. 1208507109

Ge, X., Meng, T., Tan, X., Wei, Y., Tao, Z., Yang, Z., et al. (2021). Cas14a1-mediated Nucleic Acid Detectifon Platform for Pathogens. Biosens. Bioelectron. 189, 113350. doi:10.1016/j.bios.2021.113350

Gong, S., Zhang, S., Wang, X., Li, J., Pan, W., Li, N., et al. (2021). Strand Displacement Amplification Assisted CRISPR-Cas12a Strategy for Colorimetric Analysis of Viral Nucleic Acid. Anal. Chem. 93, 15216-15223. doi:10.1021/acs.analchem.1c04133

Goode, J. A., Rushworth, J. V. H., and Millner, P. A. (2015). Biosensor Regeneration: A Review of Common Techniques and Outcomes. Langmuir 31, 6267-6276. doi:10.1021/la503533g

Gootenberg, J. S., Abudayyeh, O. O., Kellner, M. J., Joung, J., Collins, J. J., and Zhang, F. (2018). Multiplexed and Portable Nucleic Acid Detection Platform with Cas13, Cas12a, and Csm6. Science 360, 439-444. doi:10.1126/science. aaq0179

Gootenberg, J. S., Abudayyeh, O. O., Lee, J. W., Essletzbichler, P., Dy, A. J., Joung, J., et al. (2017). Nucleic Acid Detection with CRISPR-Cas13a/C2c2. Science 356, 438-442. doi:10.1126/science.aam9321

Guilinger, J. P., Thompson, D. B., and Liu, D. R. (2014). Fusion of Catalytically Inactive Cas9 to FokI Nuclease Improves the Specificity of Genome Modification. Nat. Biotechnol. 32, 577-582. doi:10.1038/nbt.2909

Hajian, R., Balderston, S., Tran, T., deBoer, T., Etienne, J., Sandhu, M., et al. (2019). Detection of Unamplified Target Genes via CRISPR-Cas9 Immobilized on a
Graphene Field-Effect Transistor. Nat. Biomed. Eng. 3, 427-437. doi:10.1038/ s41551-019-0371-x

Han, X., Liu, Z., Zhao, L., Wang, F., Yu, Y., Yang, J., et al. (2016). Microfluidic Cell Deformability Assay for Rapid and Efficient Kinase Screening with the CRISPRCas9 System. Angew. Chem. Int. Ed. 55, 8561-8565. doi:10.1002/anie. 201601984

Harrington, L. B., Burstein, D., Chen, J. S., Paez-Espino, D., Ma, E., Witte, I. P., et al. (2018). Programmed DNA Destruction by Miniature CRISPR-Cas14 Enzymes. Science 362, 839-842. doi:10.1126/science.aav4294

Huang, D., Qian, J., Shi, Z., Zhao, J., Fang, M., and Xu, Z. (2020). CRISPR-Cas12aAssisted Multicolor Biosensor for Semiquantitative Point-of-Use Testing of the Nopaline Synthase Terminator in Genetically Modified Crops by Unaided Eyes. ACS Synth. Biol. 9, 3114-3123. doi:10.1021/acssynbio.0c00365

Huang, D., Shi, Z., Qian, J., Bi, K., Fang, M., and Xu, Z. (2021). A CRISPR-Cas12aderived Biosensor Enabling Portable Personal Glucose Meter Readout for Quantitative Detection of SARS-CoV-2. Biotechnol. Bioeng. 118, 1568-1577. doi:10.1002/bit.27673

Ibrahim, A. U., Al-Turjman, F., Sa'id, Z., and Ozsoz, M. (2020). Futuristic CRISPRBased Biosensing in the Cloud and Internet of Things Era: an Overview. Multimed Tools Appl. 1, 1-29. doi:10.1007/s11042-020-09010-5

Ishino, Y., Shinagawa, H., Makino, K., Amemura, M., and Nakata, A. (1987). Nucleotide Sequence of the Iap Gene, Responsible for Alkaline Phosphatase Isozyme Conversion in Escherichia coli, and Identification of the Gene Product. J. Bacteriol. 169, 5429-5433. doi:10.1128/jb.169.12.5429-5433.1987

Jiang, Y., Hu, M., Liu, A.-A., Lin, Y., Liu, L., Yu, B., et al. (2021). Detection of SARSCoV-2 by CRISPR/Cas12a-Enhanced Colorimetry. ACS Sens. 6, 1086-1093. doi:10.1021/acssensors.0c02365

Jinek, M., Chylinski, K., Fonfara, I., Hauer, M., Doudna, J. A., and Charpentier, E. (2012). A Programmable Dual-RNA-Guided DNA Endonuclease in Adaptive Bacterial Immunity. Science 337, 816-821. doi:10.1126/science.1225829

Joung, J., Ladha, A., Saito, M., Kim, N.-G., Woolley, A. E., Segel, M., et al. (2020a). Detection of SARS-CoV-2 with SHERLOCK One-Pot Testing. N. Engl. J. Med. 383, 1492-1494. doi:10.1056/NEJMc2026172

Joung, J., Ladha, A., Saito, M., Segel, M., Bruneau, R., Huang, M.-l. W., et al. (2020b). Point-of-care Testing for COVID-19 Using SHERLOCK Diagnostics. medRxiv 1, 1. doi:10.1101/2020.05.04.20091231

Kachwala, M. J., Smith, C. W., Nandu, N., and Yigit, M. V. (2021). Reprogrammable Gel Electrophoresis Detection Assay Using CRISPRCas12a and Hybridization Chain Reaction. Anal. Chem. 93, 1934-1938. doi:10.1021/acs.analchem.0c04949

Kaminski, M. M., Abudayyeh, O. O., Gootenberg, J. S., Zhang, F., and Collins, J. J. (2021). CRISPR-based Diagnostics. Nat. Biomed. Eng. 5, 643-656. doi:10.1038/ s41551-021-00760-7

Kannan, S., Altae-Tran, H., Jin, X., Madigan, V. J., Oshiro, R., Makarova, K. S., et al. (2021). Compact RNA Editors with Small Cas13 Proteins. Nat. Biotechnol. 1, 1. doi:10.1038/s41587-021-01030-2

Karvelis, T., Bigelyte, G., Young, J. K., Hou, Z., Zedaveinyte, R., Budre, K., et al. (2020). PAM Recognition by Miniature CRISPR-Cas12f Nucleases Triggers Programmable Double-Stranded DNA Target Cleavage. Nucleic Acids Res. 48, 5016-5023. doi:10.1093/nar/gkaa208

Kellner, M. J., Koob, J. G., Gootenberg, J. S., Abudayyeh, O. O., and Zhang, F. (2019). SHERLOCK: Nucleic Acid Detection with CRISPR Nucleases. Nat. Protoc. 14, 2986-3012. doi:10.1038/s41596-019-0210-2

Kim, H., Lee, S., Yoon, J., Song, J., and Park, H. G. (2021). CRISPR/Cas12a Collateral Cleavage Activity for Simple and Rapid Detection of Protein/small Molecule Interaction. Biosens. Bioelectron. 194, 113587. doi:10.1016/j.bios.2021. 113587

Kim, N., Kim, H. K., Lee, S., Seo, J. H., Choi, J. W., Park, J., et al. (2020). Prediction of the Sequence-specific Cleavage Activity of Cas9 Variants. Nat. Biotechnol. 38, 1328-1336. doi:10.1038/s41587-020-0537-9

Kocak, D. D., Josephs, E. A., Bhandarkar, V., Adkar, S. S., Kwon, J. B., and Gersbach, C. A. (2019). Increasing the Specificity of CRISPR Systems with Engineered RNA Secondary Structures. Nat. Biotechnol. 37, 657-666. doi:10. 1038/s41587-019-0095-1

Lander, E. S. (2016). The Heroes of CRISPR. Cell 164, 18-28. doi:10.1016/j.cell. 2015.12.041

Li, B., Shao, Z., and Chen, Y. (2021a). An Exonuclease protection and CRISPR/ Cas12a Integrated Biosensor for the Turn-On Detection of Transcription 
Factors in Cancer Cells. Analytica Chim. Acta 1165, 338478. doi:10.1016/j.aca. 2021.338478

Li, C.-Y., Zheng, B., Liu, Y.-H., Gao, J.-L., Zheng, M.-Q., Pang, D.-W., et al. (2020a). A Boosting Upconversion Luminescent Resonance Energy Transfer and Biomimetic Periodic Chip Integrated CRISPR/Cas12a Biosensor for Functional DNA Regulated Transduction of Non-nucleic Acid Targets. Biosens. Bioelectron. 169, 112650. doi:10.1016/j.bios.2020.112650

Li, D., Zhang, T., Yang, F., Yuan, R., and Xiang, Y. (2020b). Efficient and Exponential Rolling Circle Amplification Molecular Network Leads to Ultrasensitive and Label-free Detection of MicroRNA. Anal. Chem. 92, 2074-2079. doi:10.1021/acs.analchem.9b04585

Li, F., Ye, Q., Chen, M., Zhou, B., Zhang, J., Pang, R., et al. (2021b). An Ultrasensitive CRISPR/Cas12a Based Electrochemical Biosensor for Listeria Monocytogenes Detection. Biosens. Bioelectron. 179, 113073. doi:10.1016/j.bios. 2021.113073

Li, H., Li, M., Yang, Y., Wang, F., Wang, F., and Li, C. (2021c). Aptamer-Linked CRISPR/Cas12a-Based Immunoassay. Anal. Chem. 93, 3209-3216. doi:10. 1021/acs.analchem.0c04687

Li, L., Li, S., Wu, N., Wu, J., Wang, G., Zhao, G., et al. (2019a). HOLMESv2: A CRISPR-Cas12b-Assisted Platform for Nucleic Acid Detection and DNA Methylation Quantitation. ACS Synth. Biol. 8, 2228-2237. doi:10.1021/ acssynbio.9b00209

Li, S.-Y., Cheng, Q.-X., Wang, J.-M., Li, X.-Y., Zhang, Z.-L., Gao, S., et al. (2018). CRISPR-Cas12a-assisted Nucleic Acid Detection. Cell Discov 4, 20. doi:10.1038/ s41421-018-0028-z

Li, Y., Li, S., Wang, J., and Liu, G. (2019b). CRISPR/Cas Systems towards NextGeneration Biosensing. Trends Biotechnology 37, 730-743. doi:10.1016/j. tibtech.2018.12.005

Li, Y., Liu, L., and Liu, G. (2019c). CRISPR/Cas Multiplexed Biosensing: A Challenge or an Insurmountable Obstacle? Trends Biotechnology 37, 792-795. doi:10.1016/j.tibtech.2019.04.012

Li, Z., Bai, Y., You, M., Hu, J., Yao, C., Cao, L., et al. (2021d). Fully Integrated Microfluidic Devices for Qualitative, Quantitative and Digital Nucleic Acids Testing at point of Care. Biosens. Bioelectron. 177, 112952. doi:10.1016/j.bios. 2020.112952

Liu, G., Lin, Q., Jin, S., and Gao, C. (2022a). The CRISPR-Cas Toolbox and Gene Editing Technologies. Mol. Cel 82, 333-347. doi:10.1016/j.molcel.2021.12.002

Liu, L., Li, X., Ma, J., Li, Z., You, L., Wang, J., et al. (2017). The Molecular Architecture for RNA-Guided RNA Cleavage by Cas13a. Cell 170, 714-726. e710. doi:10.1016/j.cell.2017.06.050

Liu, P.-F., Zhao, K.-R., Liu, Z.-J., Wang, L., Ye, S.-Y., and Liang, G.-X. (2021b). Cas12a-based Electrochemiluminescence Biosensor for Target Amplificationfree DNA Detection. Biosens. Bioelectron. 176, 112954. doi:10.1016/j.bios.2020. 112954

Liu, T. Y., Knott, G. J., Smock, D. C. J., Desmarais, J. J., Son, S., Bhuiya, A., et al. (2021c). Accelerated RNA Detection Using Tandem CRISPR Nucleases. medRxiv 1, 1. doi:10.1101/2021.03.19.21253328

Liu, X., Bu, S., Feng, J., Wei, H., Wang, Z., Li, X., et al. (2022). Electrochemical Biosensor for Detecting Pathogenic Bacteria Based on a Hybridization Chain Reaction and CRISPR-Cas12a. Anal. Bioanal. Chem. 414, 1073-1080. doi:10. 1007/s00216-021-03733-6

Ma, L., Peng, L., Yin, L., Liu, G., and Man, S. (2021). CRISPR-Cas12aPowered Dual-Mode Biosensor for Ultrasensitive and Cross-Validating Detection of Pathogenic Bacteria. ACS Sens. 6, 2920-2927. doi:10.1021/ acssensors.1c00686

Mahas, A., Hassan, N., Aman, R., Marsic, T., Wang, Q., Ali, Z., et al. (2021). LAMPcoupled CRISPR-Cas12a Module for Rapid and Sensitive Detection of Plant DNA Viruses. Viruses 13, 466. doi:10.3390/v13030466

Makarova, K. S., Wolf, Y. I., Iranzo, J., Shmakov, S. A., Alkhnbashi, O. S., Brouns, S. J. J., et al. (2020). Evolutionary Classification of CRISPR-Cas Systems: a Burst of Class 2 and Derived Variants. Nat. Rev. Microbiol. 18, 67-83. doi:10.1038/ s41579-019-0299-x

Mali, P., Yang, L., Esvelt, K. M., Aach, J., Guell, M., DiCarlo, J. E., et al. (2013). RNA-guided Human Genome Engineering via Cas9. Science 339, 823-826. doi:10.1126/science. 1232033

Manz, A., Graber, N., and Widmer, H. M. (1990). Miniaturized Total Chemical Analysis Systems: A Novel Concept for Chemical Sensing. Sensors Actuators B: Chem. 1, 244-248. doi:10.1016/0925-4005(90)80209-I
Ming, M., Ren, Q., Pan, C., He, Y., Zhang, Y., Liu, S., et al. (2020). CRISPR-Cas12b Enables Efficient Plant Genome Engineering. Nat. Plants 6, 202-208. doi:10. 1038/s41477-020-0614-6

Mu, H.-Y., Lu, Y.-L., Hsiao, T.-H., and Huang, J.-H. (2020). Microfluidic-based Approaches for COVID-19 Diagnosis. Biomicrofluidics 14, 061504. doi:10. $1063 / 5.0031406$

Myhrvold, C., Freije, C. A., Gootenberg, J. S., Abudayyeh, O. O., Metsky, H. C., Durbin, A. F., et al. (2018). Field-deployable Viral Diagnostics Using CRISPRCas13. Science 360, 444-448. doi:10.1126/science.aas8836

Niu, C., Wang, C., Li, F., Zheng, X., Xing, X., and Zhang, C. (2021). Aptamer Assisted CRISPR-Cas12a Strategy for Small Molecule Diagnostics. Biosens. Bioelectron. 183, 113196. doi:10.1016/j.bios.2021.113196

Nosek, J., Rycovska, A., Makhov, A. M., Griffith, J. D., and Tomaska, L. (2005). Amplification of Telomeric Arrays via Rolling-circle Mechanism. J. Biol. Chem. 280, 10840-10845. doi:10.1074/jbc.M409295200

Nouri, R., Jiang, Y., Lian, X. L., and Guan, W. (2020). Sequence-Specific Recognition of HIV-1 DNA with Solid-State CRISPR-Cas12a-Assisted Nanopores (SCAN). ACS Sens. 5, 1273-1280. doi:10.1021/acssensors.0c00497

Nouri, R., Tang, Z., Dong, M., Liu, T., Kshirsagar, A., and Guan, W. (2021). CRISPR-based Detection of SARS-CoV-2: A Review from Sample to Result. Biosens. Bioelectron. 178, 113012. doi:10.1016/j.bios.2021.113012

Oost, J. v. d. (2013). New Tool for Genome Surgery. Science 339, 768-770. doi:10. $1126 /$ science. 1234726

Ortiz, M., Jauset-Rubio, M., Kodr, D., Simonova, A., Hocek, M., and O'Sullivan, C. K. (2022). Solid-phase Recombinase Polymerase Amplification Using Ferrocene-Labelled dNTPs for Electrochemical Detection of Single Nucleotide Polymorphisms. Biosens. Bioelectron. 198, 113825. doi:10.1016/j. bios.2021.113825

Park, J. S., Hsieh, K., Chen, L., Kaushik, A., Trick, A. Y., and Wang, T. H. (2021). Digital CRISPR/Cas-Assisted Assay for Rapid and Sensitive Detection of SARSCoV-2. Adv. Sci. 8, 2003564. doi:10.1002/advs.202003564

Patchsung, M., Jantarug, K., Pattama, A., Aphicho, K., Suraritdechachai, S., Meesawat, P., et al. (2020). Clinical Validation of a Cas13-Based Assay for the Detection of SARS-CoV-2 RNA. Nat. Biomed. Eng. 4, 1140-1149. doi:10. 1038/s41551-020-00603-x

Piepenburg, O., Williams, C. H., Stemple, D. L., and Armes, N. A. (2006). DNA Detection Using Recombination Proteins. Plos Biol. 4, e204. doi:10.1371/ journal.pbio.0040204

Qi, L. S., Larson, M. H., Gilbert, L. A., Doudna, J. A., Weissman, J. S., Arkin, A. P., et al. (2013). Repurposing CRISPR as an RNA-Guided Platform for Sequencespecific Control of Gene Expression. Cell 152, 1173-1183. doi:10.1016/j.cell. 2013.02.022

Qiao, B., Xu, J., Yin, W., Xin, W., Ma, L., Qiao, J., et al. (2021). "Aptamer-locker" DNA Coupling with CRISPR/Cas12a-guided Biosensing for High-Efficiency Melamine Analysis. Biosens. Bioelectron. 183, 113233. doi:10.1016/j.bios.2021. 113233

Qin, P., Park, M., Alfson, K. J., Tamhankar, M., Carrion, R., Patterson, J. L., et al. (2019). Rapid and Fully Microfluidic Ebola Virus Detection with CRISPRCas13a. ACS Sens. 4, 1048-1054. doi:10.1021/acssensors.9b00239

Qing, M., Chen, S. L., Sun, Z., Fan, Y., Luo, H. Q., and Li, N. B. (2021). Universal and Programmable Rolling Circle Amplification-CRISPR/Cas12a-Mediated Immobilization-free Electrochemical Biosensor. Anal. Chem. 93, 7499-7507. doi:10.1021/acs.analchem.1c00805

Qiu, E., Jin, S., Xiao, Z., Chen, Q., Wang, Q., Liu, H., et al. (2021). CRISPR-based Detection of Helicobacter pylori in Stool Samples. Helicobacter 26, e12828. doi:10.1111/hel.12828

Ramachandran, A., Huyke, D. A., Sharma, E., Sahoo, M. K., Huang, C., Banaei, N., et al. (2020). Electric Field-Driven Microfluidics for Rapid CRISPR-Based Diagnostics and its Application to Detection of SARS-CoV-2. Proc. Natl. Acad. Sci. USA 117, 29518-29525. doi:10.1073/pnas.2010254117

Ravi, N., Cortade, D. L., Ng, E., and Wang, S. X. (2020). Diagnostics for SARS-CoV2 Detection: A Comprehensive Review of the FDA-EUA COVID-19 Testing Landscape. Biosens. Bioelectron. 165, 112454. doi:10.1016/j.bios.2020.112454

Schmid-Burgk, J. L., Gao, L., Li, D., Gardner, Z., Strecker, J., Lash, B., et al. (2020). Highly Parallel Profiling of Cas9 Variant Specificity. Mol. Cel 78, 794-800. e798. doi:10.1016/j.molcel.2020.02.023

Sha, Y., Huang, R., Huang, M., Yue, H., Shan, Y., Hu, J., et al. (2021). Cascade CRISPR/cas Enables Amplification-free microRNA Sensing with fM-Sensitivity 
and Single-Base-Specificity. Chem. Commun. 57, 247-250. doi:10.1039/ d0cc06412b

Shen, B., Zhang, W., Zhang, J., Zhou, J., Wang, J., Chen, L., et al. (2014). Efficient Genome Modification by CRISPR-Cas9 Nickase with Minimal Off-Target Effects. Nat. Methods 11, 399-402. doi:10.1038/nmeth.2857

Sheng, Y., Zhang, T., Zhang, S., Johnston, M., Zheng, X., Shan, Y., et al. (2021). A CRISPR/Cas13a-powered Catalytic Electrochemical Biosensor for Successive and Highly Sensitive RNA Diagnostics. Biosens. Bioelectron. 178, 113027. doi:10.1016/j.bios.2021.113027

Shmakov, S., Abudayyeh, O. O., Makarova, K. S., Wolf, Y. I., Gootenberg, J. S., Semenova, E., et al. (2015). Discovery and Functional Characterization of Diverse Class 2 CRISPR-Cas Systems. Mol. Cel 60, 385-397. doi:10.1016/j. molcel.2015.10.008

Smargon, A. A., Cox, D. B. T., Pyzocha, N. K., Zheng, K., Slaymaker, I. M., Gootenberg, J. S., et al. (2017). Cas13b Is a Type VI-B CRISPR-Associated RNA-Guided RNase Differentially Regulated by Accessory Proteins Csx27 and Csx28. Mol. Cel 65, 618-630. e617. doi:10.1016/j.molcel.2016.12.023

Song, F., Wei, Y., Wang, P., Ge, X., Li, C., Wang, A., et al. (2021a). Combining Tagspecific Primer Extension and Magneto-DNA System for Cas14a-Based Universal Bacterial Diagnostic Platform. Biosens. Bioelectron. 185, 113262. doi:10.1016/j.bios.2021.113262

Song, J., Kim, S., Kim, H. Y., Hur, K. H., Kim, Y., and Park, H. G. (2021b). A Novel Method to Detect Mutation in DNA by Utilizing Exponential Amplification Reaction Triggered by the CRISPR-Cas9 System. Nanoscale 13, 7193-7201. doi:10.1039/dlnr00438g

Strecker, J., Jones, S., Koopal, B., Schmid-Burgk, J., Zetsche, B., Gao, L., et al. (2019). Engineering of CRISPR-Cas12b for Human Genome Editing. Nat. Commun. 10, 212. doi:10.1038/s41467-018-08224-4

Takeda, S. N., Nakagawa, R., Okazaki, S., Hirano, H., Kobayashi, K., Kusakizako, T., et al. (2021). Structure of the Miniature Type V-F CRISPR-Cas Effector Enzyme. Mol. Cel 81, 558-570. e553. doi:10.1016/j.molcel.2020.11.035

Tian, T., Qiu, Z., Jiang, Y., Zhu, D., and Zhou, X. (2022). Exploiting the Orthogonal CRISPR-Cas12a/Cas13a Trans-cleavage for Dual-Gene Virus Detection Using a Handheld Device. Biosens. Bioelectron. 196, 113701. doi:10.1016/j.bios.2021. 113701

Tian, T., Shu, B., Jiang, Y., Ye, M., Liu, L., Guo, Z., et al. (2021). An Ultralocalized Cas13a Assay Enables Universal and Nucleic Acid Amplification-free SingleMolecule RNA Diagnostics. ACS Nano 15, 1167-1178. doi:10.1021/acsnano. 0c08165

Tian, W., Liu, X., Wang, G., and Liu, C. (2020). A Hyperbranched TranscriptionActivated CRISPR-Cas12a Signal Amplification Strategy for Sensitive microRNA Sensing. Chem. Commun. 56, 13445-13448. doi:10.1039/d0cc06034h

Tomita, N., Mori, Y., Kanda, H., and Notomi, T. (2008). Loop-mediated Isothermal Amplification (LAMP) of Gene Sequences and Simple Visual Detection of Products. Nat. Protoc. 3, 877-882. doi:10.1038/nprot.2008.57

Tsai, S. Q., Wyvekens, N., Khayter, C., Foden, J. A., Thapar, V., Reyon, D., et al. (2014). Dimeric CRISPR RNA-Guided FokI Nucleases for Highly Specific Genome Editing. Nat. Biotechnol. 32, 569-576. doi:10.1038/nbt.2908

Tycko, J., Myer, V. E., and Hsu, P. D. (2016). Methods for Optimizing CRISPRCas9 Genome Editing Specificity. Mol. Cel 63, 355-370. doi:10.1016/j.molcel. 2016.07.004

van Dongen, J. E., Berendsen, J. T. W., Steenbergen, R. D. M., Wolthuis, R. M. F., Eijkel, J. C. T., and Segerink, L. I. (2020). Point-of-care CRISPR/Cas Nucleic Acid Detection: Recent Advances, Challenges and Opportunities. Biosens. Bioelectron. 166, 112445. doi:10.1016/j.bios.2020.112445

Vandenberg, O., Martiny, D., Rochas, O., van Belkum, A., and Kozlakidis, Z. (2021). Considerations for Diagnostic COVID-19 Tests. Nat. Rev. Microbiol. 19, 171-183. doi:10.1038/s41579-020-00461-z

Vincent, M., Xu, Y., and Kong, H. (2004). Helicase-dependent Isothermal DNA Amplification. EMBO Rep. 5, 795-800. doi:10.1038/sj.embor.7400200

Wang, D.-X., Wang, J., Du, Y.-C., Ma, J.-Y., Wang, S.-Y., Tang, A.-N., et al. (2020). CRISPR/Cas12a-based Dual Amplified Biosensing System for Sensitive and Rapid Detection of Polynucleotide Kinase/phosphatase. Biosens. Bioelectron. 168, 112556. doi:10.1016/j.bios.2020.112556

Wang, M., Han, D., Zhang, J., Zhang, R., and Li, J. (2021a). High-fidelity Detection of DNA Combining the CRISPR/Cas9 System and Hairpin Probe. Biosens. Bioelectron. 184, 113212. doi:10.1016/j.bios.2021.113212
Wang, Q., Liu, X., Zhou, J., Yang, C., Wang, G., Tan, Y., et al. (2019). The CRISPRCas13a Gene-Editing System Induces Collateral Cleavage of RNA in Glioma Cells. Adv. Sci. 6, 1901299. doi:10.1002/advs.201901299

Wang, X., Chen, X., Chu, C., Deng, Y., Yang, M., Huo, D., et al. (2021b). Naked-eye Detection of Site-specific ssRNA and ssDNA Using PAMmer-Assisted CRISPR/Cas9 Coupling with Exponential Amplification Reaction. Talanta 233, 122554. doi:10.1016/j.talanta.2021.122554

Wang, X., Zhou, S., Chu, C., Yang, M., Huo, D., and Hou, C. (2021c). Dual Methylation-Sensitive Restriction Endonucleases Coupling with an RPAAssisted CRISPR/Cas13a System (DESCS) for Highly Sensitive Analysis of DNA Methylation and its Application for Point-of-Care Detection. ACS Sens. 6, 2419-2428. doi:10.1021/acssensors.1c00674

Wang, X., Zhou, S., Chu, C., Yang, M., Huo, D., and Hou, C. (2021d). Targetinduced Transcription Amplification to Trigger the Trans-cleavage Activity of CRISPR/Cas13a (TITAC-Cas) for Detection of Alkaline Phosphatase. Biosens. Bioelectron. 185, 113281. doi:10.1016/j.bios.2021.113281

White, C. W., Kilpatrick, L. E., Pfleger, K. D. G., and Hill, S. J. (2021). A Nanoluciferase Biosensor to Investigate Endogenous Chemokine Secretion and Receptor Binding. iScience 24, 102011. doi:10.1016/j.isci.2020.102011

Wu, H., Chen, Y., Shi, Y., Wang, L., Zhang, M., Wu, J., et al. (2021a). Carrying Out Pseudo Dual Nucleic Acid Detection from Sample to Visual Result in a Polypropylene Bag with CRISPR/Cas12a. Biosens. Bioelectron. 178, 113001. doi:10.1016/j.bios.2021.113001

Wu, H., Chen, Y., Yang, Q., Peng, C., Wang, X., Zhang, M., et al. (2021b). A Reversible Valve-Assisted Chip Coupling with Integrated Sample Treatment and CRISPR/Cas12a for Visual Detection of Vibrio Parahaemolyticus. Biosens. Bioelectron. 188, 113352. doi:10.1016/j.bios.2021.113352

Wu, J., Mukama, O., Wu, W., Li, Z., Habimana, J. D. D., Zhang, Y., et al. (2020). A CRISPR/Cas12a Based Universal Lateral Flow Biosensor for the Sensitive and Specific Detection of African Swine-Fever Viruses in Whole Blood. Biosensors 10, 203. doi:10.3390/bios 10120203

Xing, S., Lu, Z., Huang, Q., Li, H., Wang, Y., Lai, Y., et al. (2020). An Ultrasensitive Hybridization Chain Reaction-Amplified CRISPR-Cas12a Aptasensor for Extracellular Vesicle Surface Protein Quantification. Theranostics 10, 10262-10273. doi:10.7150/thno.49047

Xu, C., Zhou, Y., Xiao, Q., He, B., Geng, G., Wang, Z., et al. (2021a). Programmable RNA Editing with Compact CRISPR-Cas13 Systems from Uncultivated Microbes. Nat. Methods 18, 499-506. doi:10.1038/s41592-021-01124-4

Xu, X., Chemparathy, A., Zeng, L., Kempton, H. R., Shang, S., Nakamura, M., et al. (2021b). Engineered Miniature CRISPR-Cas System for Mammalian Genome Regulation and Editing. Mol. Cel 81, 4333-4345. e4334. doi:10.1016/j.molcel. 2021.08.008

Yan, W. X., Chong, S., Zhang, H., Makarova, K. S., Koonin, E. V., Cheng, D. R., et al. (2018). Cas13d Is a Compact RNA-Targeting Type VI CRISPR Effector Positively Modulated by a WYL-Domain-Containing Accessory Protein. Mol. Cel 70, 327-339. e325. doi:10.1016/j.molcel.2018.02.028

Yan, W. X., Hunnewell, P., Alfonse, L. E., Carte, J. M., Keston-Smith, E., Sothiselvam, S., et al. (2019). Functionally Diverse Type V CRISPR-Cas Systems. Science 363, 88-91. doi:10.1126/science.aav7271

Yang, Y., Liu, J., and Zhou, X. (2021). A CRISPR-Based and post-amplification Coupled SARS-CoV-2 Detection with a Portable Evanescent Wave Biosensor. Biosens. Bioelectron. 190, 113418. doi:10.1016/j.bios.2021.113418

Yin, J., Suo, Y., Zou, Z., Sun, J., Zhang, S., Wang, B., et al. (2019). Integrated Microfluidic Systems with Sample Preparation and Nucleic Acid Amplification. Lab. Chip 19, 2769-2785. doi:10.1039/c9lc00389d

Yin, K., Ding, X., Li, Z., Zhao, H., Cooper, K., and Liu, C. (2020). Dynamic Aqueous Multiphase Reaction System for One-Pot CRISPR-Cas12a-Based Ultrasensitive and Quantitative Molecular Diagnosis. Anal. Chem. 92, 8561-8568. doi:10. 1021/acs.analchem.0c01459

You, Y., Zhang, P., Wu, G., Tan, Y., Zhao, Y., Cao, S., et al. (2021). Highly Specific and Sensitive Detection of Yersinia pestis by Portable Cas12aUPTLFA Platform. Front. Microbiol. 12, 700016. doi:10.3389/fmicb.2021. 700016

Yu, F., Zhang, K., Wang, Y., Li, D., Cui, Z., Huang, J., et al. (2021). CRISPR/Cas12abased On-Site Diagnostics of Cryptosporidium Parvum IId-Subtype-Family from Human and Cattle Fecal Samples. Parasites Vectors 14, 208. doi:10.1186/ s13071-021-04709-2 
Yuan, T., Mukama, O., Li, Z., Chen, W., Zhang, Y., de Dieu Habimana, J., et al. (2020). A Rapid and Sensitive CRISPR/Cas12a Based Lateral Flow Biosensor for the Detection of Epstein-Barr Virus. Analyst 145, 6388-6394. doi:10.1039/ d0an00663g

Yue, H., Huang, M., Tian, T., Xiong, E., and Zhou, X. (2021a). Advances in Clustered, Regularly Interspaced Short Palindromic Repeats (CRISPR)-Based Diagnostic Assays Assisted by Micro/Nanotechnologies. ACS Nano 15, 7848-7859. doi:10.1021/acsnano.1c02372

Yue, H., Shu, B., Tian, T., Xiong, E., Huang, M., Zhu, D., et al. (2021b). Droplet Cas12a Assay Enables DNA Quantification from Unamplified Samples at the SingleMolecule Level. Nano Lett. 21, 4643-4653. doi:10.1021/acs.nanolett.1c00715

Zetsche, B., Gootenberg, J. S., Abudayyeh, O. O., Slaymaker, I. M., Makarova, K. S., Essletzbichler, P., et al. (2015). Cpf1 Is a Single RNA-Guided Endonuclease of a Class 2 CRISPR-Cas System. Cell 163, 759-771. doi:10.1016/j.cell.2015.09.038

Zetsche, B., Heidenreich, M., Mohanraju, P., Fedorova, I., Kneppers, J., DeGennaro, E. M., et al. (2017). Multiplex Gene Editing by CRISPR-Cpf1 Using a Single crRNA Array. Nat. Biotechnol. 35, 31-34. doi:10.1038/nbt.3737

Zhang, K., Fan, Z., Yao, B., Ding, Y., Zhao, J., Xie, M., et al. (2021a). Exploring the Trans-cleavage Activity of CRISPR-Cas12a for the Development of a Mxene Based Electrochemiluminescence Biosensor for the Detection of Siglec-5. Biosens. Bioelectron. 178, 113019. doi:10.1016/j.bios.2021.113019

Zhang, T., Zhou, W., Lin, X., Khan, M. R., Deng, S., Zhou, M., et al. (2021b). Lightup RNA Aptamer Signaling-CRISPR-Cas13a-Based Mix-And-Read Assays for Profiling Viable Pathogenic Bacteria. Biosens. Bioelectron. 176, 112906. doi:10. 1016/j.bios.2020.112906

Zhang, W. S., Pan, J., Li, F., Zhu, M., Xu, M., Zhu, H., et al. (2021c). Reverse Transcription Recombinase Polymerase Amplification Coupled with CRISPR-Cas12a for Facile and Highly Sensitive Colorimetric SARSCoV-2 Detection. Anal. Chem. 93, 4126-4133. doi:10.1021/acs. analchem.1c00013
Zhao, J., Tan, Z., Wang, L., Lei, C., and Nie, Z. (2021a). A Ligation-Driven CRISPRCas Biosensing Platform for Non-nucleic Acid Target Detections. Chem. Commun. 57, 7051-7054. doi:10.1039/d1cc02578c

Zhao, Q., Pan, Y., Luan, X., Gao, Y., Zhao, X., Liu, Y., et al. (2021b). Nanoimmunosorbent Assay Based on Cas12a/crRNA for Ultra-sensitive Protein Detection. Biosens. Bioelectron. 190, 113450. doi:10.1016/j.bios.2021.113450

Zhou, T., Huang, M., Lin, J., Huang, R., and Xing, D. (2021). High-Fidelity CRISPR/Cas13a Trans-cleavage-triggered Rolling Circle Amplified DNAzyme for Visual Profiling of MicroRNA. Anal. Chem. 93, 2038-2044. doi:10.1021/acs.analchem.0c03708

Zhu, X., Wang, X., Li, S., Luo, W., Zhang, X., Wang, C., et al. (2021). Rapid, Ultrasensitive, and Highly Specific Diagnosis of COVID-19 by CRISPR-Based Detection. ACS Sens. 6, 881-888. doi:10.1021/acssensors.0c01984

Conflict of Interest: The authors declare that the research was conducted in the absence of any commercial or financial relationships that could be construed as a potential conflict of interest.

Publisher's Note: All claims expressed in this article are solely those of the authors and do not necessarily represent those of their affiliated organizations or those of the publisher, the editors, and the reviewers. Any product that may be evaluated in this article, or claim that may be made by its manufacturer, is not guaranteed or endorsed by the publisher.

Copyright (C) 2022 Chen, Li, Xu and Yang. This is an open-access article distributed under the terms of the Creative Commons Attribution License (CC BY). The use, distribution or reproduction in other forums is permitted, provided the original author(s) and the copyright owner(s) are credited and that the original publication in this journal is cited, in accordance with accepted academic practice. No use, distribution or reproduction is permitted which does not comply with these terms. 